men in later years", it was in matters of state that "his confidence and vision proved correct even in particulars".

Wormald, surely the ablest of our elder historians, here firmly sets Bacon in his epoch as the budding statesman of Elizabeth I's time bidding to inherit the Cecil legacy under James I. For Bacon, a humanist and a man of religion, the truths of divinity were confirmed by history and experience; and although Truth was (he declared) the daughter of time not of authority, time had for him only validated divine authority. Yet although history was judged by Bacon to be the least exceptionable branch of human knowledge, it is impossible, Wormald affirms, that it "should have stood higher in Bacon's reckoning than philosophy". Philosophy permitted the highest exercise of human reason, subject to the provisos that "all knowledge is limited by religion, and to be referred to use and action". (Pure mathematics referred to neither.)

The Bacon of court and cabinet studied here was no godfather to the Royal Society or to industrial science, nor was it his logical "machine" (Bacon's word) that transformed seventeenth-century science. Wormald discloses not a philosopher in the modern sense but a politician, scholar and moralist who indeed wrote science like the Lord Chancellor that Bacon became. The author points out that the logical machine was never tested - for the natural history to which it must be applied was never assembled - and so its defects, already seen by such close successors of Bacon as Marin Mersenne, were never revealed.

Wormald's portrait, ranging as it does over the whole of a life and a vast mental range, is not drawn in strong lines but in delicate shading. His prose is often as elliptical as his subject's, and many sentences must be read twice. Like Bacon's road to true knowledge, his way ascends and descends through Bacon's multifarious writings. His book has no obvious structure, chronological or other, and is often (deliberately) repetitive. He cheerfully flouts the canons of 'contextual' history and does not hesitate to leap forward in his comments to the nineteenth and twentieth centuries. To my mind, this rich, complex study repays the effort that must be expended on it: to make Bacon tidy is to distort him. To fail to relate his Essays to the Novum Organum is to risk incomprehension. Bacon's extant writings are so large, his exposition so elusive perhaps befitting a contemporary of the metaphysical poets - and his topics are so varied that debate about them will not soon cease; Wormald shows what a vast, and at the same time flawed, intellectual giant Bacon was.

A. Rupert Hall is at 14 Ball Lane, Tackley, Oxfordshire OX5 3AG, UK.

\section{Ways of seeing}

\section{Patricia S. Goldman-Rakic}

A Vision of the Brain. By Semir Zeki. Blackwell Scientific: 1993. Pp. 366. £18.95, \$36.95.

THE primate visual system is usually considered the model example of integrative neurobiology and is the only 'systems' research to be acknowledged by a Nobel prize (to David Hubel and Torsten Wiesel in 1981). All students of neuroscience know about the pathways from retina to cerebral cortex, ocular dominance, orientation columns and cytochrome oxidase blobs in the primary visual cortex, as well as the developmental permutations of the numerous connections in the visual cortex and its physiological properties. These details are plainly exposed in every modern textbook of neurobiology and discussed in many review articles. It may be wondered whether a book on the visual system is necessary and what it could contribute beyond all this material.

Yet Semir Zeki's A Vision of the Brain is new and fresh because it is at once thematic, evaluative and didactic. The primary facts of visual cortex structure and function are reviewed with clarity and skill, and, for anyone who is unfamiliar with the visual system, the book will provide a highly readable, convenient, clear and up-to-date summary, though not of all components, nor all levels of analysis (such as the molecular biology or biophysics of colour-sensitive receptors in the retina). The central theme, expertly covered, is the cortical basis of colour vision. The clinical and experimental evidence for the existence of a specialized colour centre outside the primary visual cortex is explained, evaluated and discussed in an exemplary socratic style. The history of ideas about visual specialization, viewed by someone who has been part of this history for the past 25 years, is especially interesting. Zeki's account of blind spots and revelations leading to our present highly sophisticated knowledge of the architecture of vision is enlightening. It will be of broad appeal and educational value to neuroscience graduate students, an invaluable introduction for nonneuroscientists, especially psychologists, computer scientists, historians of science and philosphers, and an encouragement to those scientists who find themselves 'swimming upstream'.

The science is strategically interwoven with historical and critical commentary. For example, in Chapter 10, Zeki captivates interest with the startling sentence: "In 1983, a miracle happened" to introduce Zihl's pivotal clinical case of motion blindness in a patient with all other aspects of visual processing otherwise pre- served. Chapter 13 is a diversion that champions anatomy and physiology and may displease a few computational and computer scientists: "To become meaningful to the experimental neurobiologist, the computational neurobiologist needs the facts of the nervous system even more than the experimental neurobiologist needs the theory generated by the computational neurobiologist. . Theory has always been of importance in the collection of facts, including even the mere anatomical facts." David Marr's much admired book Vision and the popular "what and where doctrine" are also discussed, critically and fairly.

Does the visual system provide a vision of the brain? It is obvious that as a prototype, it has instructed and inspired the study of many other areas of the cortex. But columns were first described in the somatosensory cortex, and functional specialization in the motor cortex and the language areas of the frontal and temporal lobes. As pointed out by Zeki, knowledge of other systems, such as the motor cortex, should have had more influence than they did on visual scientists, but important discoveries were ignored. Visual scientists tend to be myopic when it comes to knowledge beyond vision. The problems of binding and integration, for example, may not be solved within the visual system. Nevertheless, it is difficult to argue with the thesis that the operating principles of this system provide, particularly with respect to parallel processing, the key to the functional organization of the cortex as a whole.

The book is enjoyable to read, not only because of its intellectually appealing content but also because it is beautifully produced and well illustrated. Short chapters, each designed to make a specific point, allow it to be read in parts, put down and picked up again, as with a good novel. Most important, the book shows how powerful ideas can blind us as well as lead us to reality; it is about belief systems and how our stated or tacit theories colour our perception of facts, even in the "objective' world of science. This is not new in itself but it is something we need to be reminded of from time to time. That is why the book is important reading for seasoned investigators, budding scientists and undergraduates. If it encourages scientists to acknowledge their blindspots and consider how what they know fits with the knowledge they have eschewed, it will have greatly widened the field of view.

Patricia S. Goldman-Rakic is in the Section of Neurobiology, Yale School of Medicine, New Haven, Connecticut 06511, USA.

- New in paperback is Vision: Coding and Efficiency edited by Colin Blakemore (CUP, $£ 22.95, \$ 34.95)$. Reviewed in Nature 351, $24 ; 1991$ 